\section{The GDC - lifting the lid. Part 5: illegal practice}

\author{
H. Mathewson ${ }^{1}$ and D. Rudkin²
}

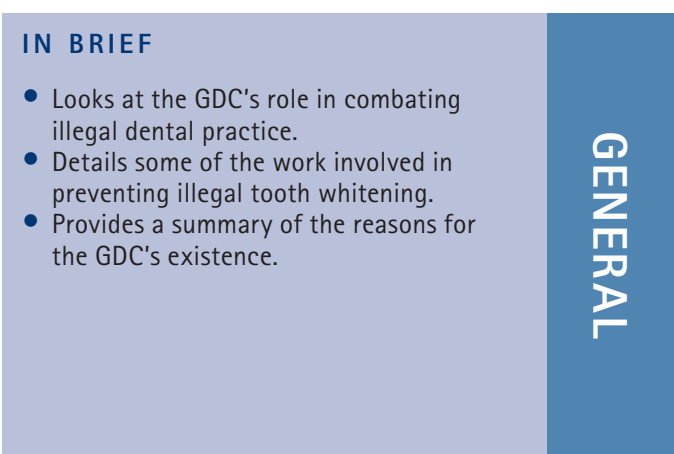

In its primary role of protecting the public the General Dental Council has many tools at its disposal, one of which is pursing those who seek to practise dentistry illegally. Such illegal practice takes several different forms: dentists who have been erased or removed from the register but continue to practise, unregistered dental technicians who practise dentistry, and beauty salons that offer tooth whitening. Consequently a variety of approaches is required in order to apprehend the miscreant and persuade, prevent and even prosecute them in the process of stopping their illegal activities. The fifth and final part of our series on the GDC discusses the modus operandi of the legal department's work in this important area.

In previous articles we have lifted the lid on the work the GDC does to regulate dentists and dental care professionals. There is another group where the GDC takes a very different approach - illegal dental workers who are not regulated and work outside the law.

Solicitor Shareen Law (Fig. 1) is one of three lawyers in the Council's legal team who prosecutes under the 1984 Dentists Act. 'There is no legal onus on us to prosecute, but we take illegal practice very seriously,' says Shareen, who has been advising the GDC and prosecuting illegal practitioners for four years.

'The work varies enormously. Unusually, we bring civil and criminal cases - most lawyers specialise in one or the

THE GDC - LIFTING THE LID
1. Professionalism and standards
2. Registration
3. Education, CPD and revalidation
4. Fitness to practise
5. Illegal practice

${ }^{1}$ President, ${ }^{2 *}$ Chief Executive and Registrar, General Dental Council, 37 Wimpole Street, London, W1G 8D0 ${ }^{*}$ Correspondence to: Mr Duncan Rudkin Email:drudkin@gdc-uk.org

Refereed Paper

DOI: 10.1038/sj.bdj.2008.663

${ }^{\oplus}$ British Dental Journal 2008; 205: 153-155 other. Every case seems to feature an aspect that we haven't met before. It's fascinating - and challenging! - to see how safeguarding the public works in practice. Registered dentists overwhelmingly meet high standards that illegal practitioners don't.'

Illegal practice cases include dentists who have been erased or removed from the register but continue to practise, unregistered dental technicians who practise dentistry, and beauty salons that offer tooth whitening. Shareen has seen a variety of cases. Dentists may practise in their own country, arrive here in the UK and work without any apparent thought of registration. Others may have been removed from the register because they have not paid but still continue to practise, despite the fact that their indemnity insurance might be void.

Dental technicians can, of course, repair dentures but sometimes they can go beyond what the law allows. 'They can be very serious cases, leaving patients suffering physically and financially. We prosecute year in, year out, and some are fined thousands of pounds, but many accept the commercial risk. We alert the press, but it's a continuing battle,' says Shareen. Occasionally the GDC has to prosecute more than once. One repeat offender, who pleaded guilty to 14 offences, was this year ordered to pay compensation of $£ 1,322$ to three

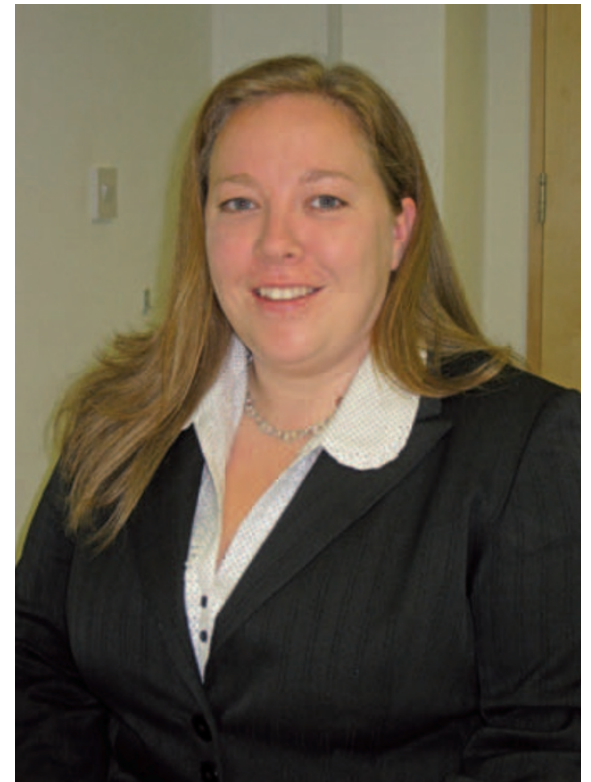

Fig. 1 Shareen Law, one of three lawyers on the GDC's legal team

patients, given 100 hours of community service and ordered to contribute to the GDC's costs.

\section{Tooth whitening}

Tooth whitening is another huge issue. 'Assessing people's teeth, putting your hands in their mouths, painting a substance on their teeth and permanently changing their appearance - we say that's dentistry, and as such should be undertaken by people registered with us,' says Shareen. She believes, as the GDC does, that you, as a dentist, are better at tooth 
whitening than, say, a beauty therapist, because you can take general health into account, including checking the soft palate and the condition of the teeth. You know the risks and you have, as she puts it, 'five years' training in delving into my mouth'. You, as a dentist, also have professional indemnity insurance, rather than general insurance.

What does the tooth whitening industry say? 'Well, we can't prosecute them for passing themselves off as dentists - using a "protected title" - because they tend to describe themselves as smile therapists, or something similar.' They argue that they are not undertaking invasive dental work, such as crowns or fillings; they say it is cosmetic. It is not. As a result, beauticians can go on a one-day course and next day bleach people's teeth, with potentially horrendous results. What complicates things is that you, as a member of the public, can walk into a high street chemist tomorrow and buy a kit that you can perfectly legally use to whiten - or try to whiten - your own teeth.

The Council's first step has been to write to salons, pointing out that they are undertaking an illegal activity. Sometimes, at this point, the salons hold up their hands and want no more to do with tooth whitening. Many have invested a lot of money in becoming a 'qualified smile therapist', 'to be sent off into the world to paint toxic substances in people's mouths', as Shareen puts it.

In one case, a salon owner pleaded that she had just paid out for expensive kit: the GDC supplied evidence that the equipment was intended to be used for illegal purposes and she got her money back. We will definitely offer such help again. If a salon has been warned and perhaps gives some spurious justification - for instance, that 'the rules only apply to the NHS' - then the GDC investigates. We want them to know that we are combative - on behalf of patients.

Currently we are investigating a large number of beauty salons and will decide in time which to prosecute. You know, more than most, that the bleach used in tooth whitening can be very strong and the soft tissue in mouths can be extremely sensitive. This can be a dangerous combination, as one victim found out.
In 2006, the GDC prosecuted a sales representative who demonstrated tooth whitening equipment on a Norfolk dental nurse. She was badly burned as a result. It was the representative's first offence and he pleaded guilty. The fine: $£ 750$, although he was ordered to pay compensation to the nurse, and our costs. That may be enough to deter some illegal tooth whiteners. 'If we have a patient willing to go to court alleging harm, we will prosecute tomorrow. We have three cases in the offing: all with witnesses who allege harm. Their testimony is crucial. Prioritising such cases is our strategy. Most are pretty open and shut - or we hope they are. We think we can win.'

The illegal practice of dentistry is a crime, but it is not always one that is recognised as such by the courts, particularly if there are no apparent victims. A sustained campaign to counter tooth whitening by unregistered individuals may help to change all that. We will give it all that we've got.

\section{Why the GDC exists}

We know - you tell us - that the GDC can appear remote and monolithic, uncaring and bureaucratic. We hope this series has suggested otherwise. The GDC is changing, quickly and for the better. If the GDC did not exist, would you have to invent it? We think so. We hope this series has given some reasons why.

We register you and your colleagues, of course, and that is a massive undertaking, particularly now we register the entire dental team. With your help as a registrant, we set the standards expected of you and those who would join you in the profession.

We help regulate the education that helps deliver those standards, and the continuing professional development with, in future, the revalidation process - that ensures that your education is up to date. We deal with cases where those standards have fallen short, leading to complaints and issues of fitness to practise. We chase those who are practising dentistry illegally - as detailed above.

In short, we register dental professionals, to maintain standards, to protect patients. Patients are our focus. Protecting patients is what we're here for.
But that is enough about us. Sometimes, when one or other of us is talking to dentists, we ask them to imagine themselves in the position of their patient. Walk around in their shoes. Look at the world through their eyes. Imagine receiving treatment, not as a dentist in the hands of another dentist, but as a lay patient.

Imagine unknowing everything you spent so much effort learning. Imagine being apprehensive; imagine not understanding any of the language. Imagine being in an alien environment - how you yourself might feel before a Conduct Committee.

Now we are looking at the world through this patient's eyes, what are her assumptions? She probably made several, without even realising it, when she booked her appointment. She made several more as she walked into the surgery and sat down. As she opened her mouth and put her head back? There - more assumptions. Professionalism is partly about making good on the assumptions our patients make, whether they are aware of them or not.

When I am deciding to go to the dentist, I might or might not be aware of making these assumptions. If I am very unusual, I might actually try to check them out. But by and large I will not. Even if I wanted to check, as a lay patient I probably do not have a clue about how to tell a good dentist from a bad one. And because there is this building with a sign saying 'Dental Surgery' and there are people in there doing dentistry, I assume all these things.

I assume they have the knowledge that I lack, and the skills to treat me.

I assume that at the very least I am not going to come out of there worse off - at least, when it comes to my teeth - than when I went in.

And naturally I assume that whilst I am in there, whatever else happens I am not going to get robbed or beaten up, or humiliated, or abused, or ripped off.

All these assumptions are made in the blink of an eye. If I stopped to think about it and wanted all this proved to me directly I would never go anywhere near a dental surgery. Think about it: in what other situation or walk of life would I go into a strange place, lie back and open 
my mouth, one of my most intimate and personal spaces, and let a stranger poke around in there with sharp instruments and pull me about and cut me and drill holes in parts of my body?

I do - we do - in our thousands every day, because, apparently on the strength of very little evidence, we trust you.

And once I start thinking about the treatment I need, and my dentist starts to tell me what they are going to do, I am into making another great raft of assumptions.

I am assuming that my dentist is not doing things that are out of date. I assume that my dentist is committed to doing a good job and continuing to learn, because I do not want to be treated by someone who has switched off and is getting rusty, whether they are 25 or 65 .

And when I am told that I need this and that doing, and this other thing could be done if I want it, I am all the time assuming that they are telling me what is good for me, not what is good for them - in that they will earn more money or because they really enjoy doing a particular procedure and are bored doing what I actually need.

And if I stop and think about it and I am half way reasonable, I will admit to assuming that dentists are not perfect any more than anyone else, and that things will sometimes go wrong. I might even accept that something might go wrong for me in particular, either because I am unlucky, or maybe because they make a mistake. But I am also assuming that if that happens, they will try to sort it out.

What if something goes wrong and I do not even realise? I assume they will tell me, even if it might get them into trouble. And if they have made a mistake they will explain it to me and try to help find a solution. And if they have made an avoidable mistake that is really bad and I suffer, I expect to be able to be compensated, whether or not they have got any money themselves. (Of course if I am thinking like that I might be going to see someone else anyway, but I am probably not aware of making these assumptions at all, remember.)

And I assume that part of the deal is that I may need to tell them information about myself because they need to know it, but they are not going to gossip about it, or leave it lying around for my next door neighbour - who is also in the waiting room - to see.

And overall I assume that there is a system or an organisation or a set of processes which make sure that all these things I am assuming are actually valid. I might not know who it is, and I am probably not that interested to find out, unless I have a major problem. But surely, somebody somewhere is looking after things?

Someone is. We are that 'somebody somewhere': the GDC. 